American J. of Engineering and Applied Sciences 3 (2): 470-475, 2010

ISSN 1941-7020

(C) 2010 Science Publications

\title{
Assessment of Useful Life of Lubricants Using Analytical Hierarchy Process (AHP) and Vector Projection Approach (VPA)
}

\author{
Surachai Bovornsethanant and Somchai Wongwises \\ Department of Mechanical Engineering, King Mongkut's University of Technology Thonburi, \\ Bangmod, Bangkok 10140
}

\begin{abstract}
Problem statement: In general, engine oil is usually changed as defined by car or lubricant manufacturers, which is according to mileage. However, it was found from past researches that, at the predefined mileage or timeframe, most lubricant is still acceptably usable and efficient. Approach: This research aimed to calculate useful life of lubricant in order to reach its maximum usefulness. The method of study began by collecting data that indicates deterioration of lubricant by increasing mileage which includes total base number, viscosity, iron and flash point. Then the data was analyzed by means of Analysis Hierarchy Process (AHP). These variables were used to construct a model for calculating appropriate useful life of lubricant by using vector projection approach. It was found from this study that the defined mileage for changing lubricant, which is generally at $5,000 \mathrm{~km}$, is not appropriate. Results: Results of the study suggest that the most appropriate mileage for change of lubricant is at $12,000 \mathrm{~km}$. Conclusion: It could be concluded that collection of data about characteristics of lubricant and use of model for calculating useful life of lubricant can define appropriate interval change of lubricant.
\end{abstract}

Key words: Analytical hierarchy process, vector projection approach, useful life of lubricant

\section{INTRODUCTION}

An interval changing lubricant of engines is very important in maintenance work because lubricant helps prevent wear and tear of frictional parts. Deterioration of lubricant can be analyzed from changing characteristics of lubricant according to duration of use. The characteristics considered include Viscosity, TAN or TBN, Flash Point and fire Point and increased amount of metal particles in lubricant-which in this study Iron is used to signalize wear and tear of various parts. Since there are several indicators of deterioration of lubricant, in traditional method, used lubricant from several timeframes were tested against acceptable standard. If any characteristic exceeds the specified standard, it is time to change lubricant. In this research, Multi-criteria decision-making method was used to determine an interval change of lubricant. Analytical Hierarchy Process (AHP) is one of popular methods which can be applied to solve multi-indicators problems. Because in this method indicators are weighted according to importance of characteristic in use, more rational relationship can be specified.

Lubrication is very important for engines. At present, car manufacturers, oil manufacturers, including feeling of cars' users, are major factors in defining suitable interval change of lubricant. However, suitable timeframe or mileage for change of lubricant has never been clearly defined.

Up to the present, there are only some previous studies concerning this problem as follows:

Sinha et al. (2000) studied the useful life of lubricants using the artificial neural network method. In this study, the critical properties of oil such as viscosity, flash point, water content, insoluble rating were used as the input value to the network. Matlab version 5 with ANN toolbox was used to run the program and the network model was trained for viscosity. The result obtained from this study indicated that the estimated rejection time was $308 \mathrm{~h}$.

Mukherjee et al. (2000) analyzed the remaining useful life of lubricant by the Fourier Transform Infrared (FTIR). A case study on Heavy Earth Moving Machinery (HEMM) in Indian mines was studied. They concluded that this method was simple and the result obtained from this method was reliable. However, this method can be utilized as the total life of the lubricant was identified.

The application of the Analytic Hierarchy Process (AHP) for selecting the best maintenance strategy was

Corresponding Author: Surachai Bovornsethanant, Department of Mechanical Engineering,

King Mongkut's University of Technology Thonburi, Bangmod, Bangkok 10140 
presented by Bevilacqua and Braglia (2000) for oil refinery. The preventive, predictive, condition-based, corrective and opportunistic maintenance which were the possible alternative were analyzed. They noted that AHP was coupled with a sensitivity analysis in order to correct the effectiveness of the procedure.

Al-Harbi (2001) applied the Analytic Hierarchy Process (AHP) in the project management. An example of contractor prequalification was presented. A sensitivity analysis was used to check the sensitivity of the final decisions. In order to simplify the methodology, the professional software (Expert choice) which was available commercially was used in this analysis.

The assessment of Remaining Useful Life (RUL) of lube oil using AHP and vector projection approach was studied by Sharma and Gandhi (2006). They used this method to identify the degradation of lubricants at an accelerated rate by operating system. The physical and chemical properties related to degradation of the lube oil were investigated. They reported that the result obtained from this study will help the maintenance and operational personnel.

Chen and Cai (2003) developed the methodology for evaluating the maintainability of the mechanical system. A number of standard guidelines were presented in this study and used to develop a set of maintainability factor. The developed methodology was called vector projection method. An example of mechanism of valve-driving system was discussed. They reported that this procedure provided a convenient method to estimate the best design.

The combination of the Analytic Hierarchy Process (AHP) and Technique for Order Preference by Similarity to Ideal Solution (TOPSIS) were developed to select an optimum maintenance strategy for a textile industry by Shyjith et al. (2008). They stated that the multifaceted factors were involved in the maintenance strategy selection. Therefore, it required the multi criteria decision-making to estimate the strategies. The results showed the most accurate decision when a maintenance policy was used.

Change of lubricant according to mileage predefined by manufacturers could be done while the lubricant is still usable. Currently, Thailand uses about 292 L of lubricant per year. Each change of lubricant produces waste which should be disposed of and loss from ineffective use. Moreover, engines have been improved to have higher performance and lubricant has also been improved to have higher efficiency. Hence, lubricant should have longer useful life.

The objective of this research is to apply the Analytical Hierarchy Process (AHP) and Vector
Projection Approach to determine remaining useful life of lubricant in order to achieve its maximum usefulness as well as to conserve valuable resources and save production cost.

Theories used for calculating useful life of lubricant: All variables were weighted by using Analytical Hierarchy Process (AHP) to define significant weight of each variable (Saaty, 1994). The method consists of the following steps:

- Define weight for each variable according to its importance:

$$
\mathrm{V}=\left\{\mathrm{P}_{1}, \mathrm{P}_{2}, \mathrm{P}_{3}, \mathrm{P}_{4}, \ldots \ldots, \mathrm{P}_{\mathrm{i}}\right\}, \mathrm{i}=1,2,3, \ldots, \mathrm{n}
$$

where $\mathrm{n}$ is number of variable used in AHP process.

- Construct a matrix of $n \times n$ to compare against decision-making criteria:

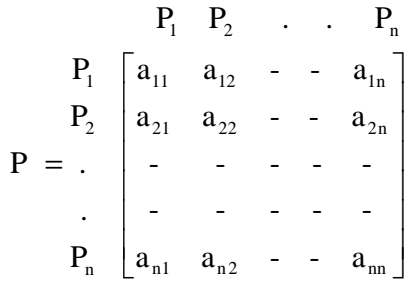

Matrix $P$ contains members of $a_{i j}$ which derived from a comparison of importance of $P_{1}$ which is higher than the importance of $\mathrm{P}_{2}$ according to Table 1. Values of $a_{\mathrm{ji}}$ will be reversed values of $\mathrm{a}_{\mathrm{ij}}\left(\mathrm{a}_{\mathrm{ji}}=1 / \mathrm{a}_{\mathrm{ij}}\right)$. This matrix is called "reciprocal matrix".

- Use the reciprocal matrix to calculate Consistency Ratio (CR) of data by:

- Find value of $\lambda_{\max }$

- Find Consistency Index (CI) using

$$
\mathrm{CI}=\frac{\lambda_{\max }-\mathrm{n}}{\mathrm{n}-1}(\text { Table } 2)
$$

Table 1: Pair wise comparison in AHP preferences (Saaty, 1994)

\begin{tabular}{ll}
\hline Ratings & Judgment/preference \\
\hline 9 & Extremely preferred \\
7 & Very strongly preferred \\
5 & Strongly preferred \\
3 & Moderately preferred \\
1 & Equally preferred \\
\hline
\end{tabular}

Note: $2,4,6,8$ are in the middle scale

Table 2: Assigning of random consistency Index (RI) (Saaty, 1994; Saaty and Kearns, 1991)

\begin{tabular}{lllllllllll}
\hline Size of matrix & 1 & 2 & 3 & 4 & 5 & 6 & 7 & 8 & 9 & 10
\end{tabular}

\begin{tabular}{lllllllllll} 
Random consistency index & 0 & 0 & 0.58 & 0.90 & 1.12 & 1.24 & 1.32 & 1.41 & 1.45 & 1.49 \\
\hline
\end{tabular} 
- Find Consistency Ratio (CR) from $\mathrm{CR}=\frac{\mathrm{CI}}{\mathrm{RI}}$ by using RI value from Table 3. If CR is $<0.1$, weight of variable is accurate.

- Find importance value of each variable from Normalized matrix:

$$
\mathrm{W}=\left[\begin{array}{l}
\mathrm{W}_{1} \\
\mathrm{~W}_{2} \\
\mathrm{~W}_{3} \\
\mathrm{~W}_{4}
\end{array}\right]
$$

Vector projection approach: Value of each variable at increased kilometer does not show similar trend. Some variable has downward trend while some has upward trend. From the field test, value of each variable could be written into the following matrix:

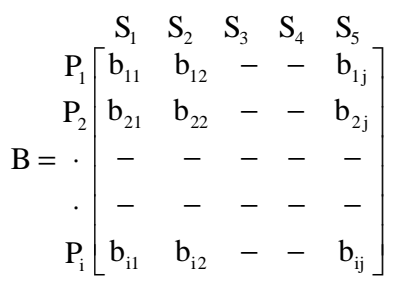

$\mathrm{b}_{\mathrm{ij}}$ is a value from field test.

Therefore, all variables have to be made to show the same trend in order to summarize into one conclusion and compare to acceptable value of the oil.

From the formula:

\section{For variables with upward trend:}

$$
\mathrm{D}_{\mathrm{ij}}=\left[\frac{\mathrm{b}_{\mathrm{ij}}-\text { UpperLimit }}{\text { LowerLimit }- \text { UpperLimit }}\right]
$$

For variables with downward trend:

$$
\mathrm{D}_{\mathrm{ij}}=\left[\frac{\mathrm{b}_{\mathrm{ij}}-\text { LowerLimit }}{\text { UpperLimit }- \text { LowerLimit }}\right]
$$

A matrix which compares increased mileage (S) with various variables $(\mathrm{P})$ is as follows:

Table 3: Comparison of matrix of pair wise and its reciprocal

\begin{tabular}{lllll}
\hline Criterion for decision making & P1 & P2 & P3 & P4 \\
\hline TBN P1 & 1 & 1 & 7 & 8 \\
Kinematic viscosity at $100^{\circ} \mathrm{C}$ P2 & 1 & 1 & 6 & 7 \\
Flash point P3 & $1 / 7$ & $1 / 6$ & 1 & 1 \\
Iron P4 & $1 / 8$ & $1 / 7$ & 1 & 1 \\
Summation & 2.2678 & 2.3095 & 15 & 17 \\
\hline
\end{tabular}

$$
\begin{aligned}
& \begin{array}{lllll}
S_{1} & S_{2} & \ldots & S_{j}
\end{array}
\end{aligned}
$$

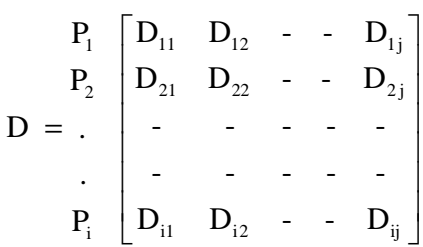

Matrix D and matrix $\mathrm{W}$ are used to calculate remaining useful life of lubricant by finding matrix $\mathrm{E}$ from multiplying matrix $\mathrm{W}$ with matrix $\mathrm{D}$ :

$$
\begin{aligned}
& {[\mathrm{E}]=[\mathrm{W}][\mathrm{D}]} \\
& \begin{array}{lllll}
S_{1} & S_{2} & \ldots & S_{j}
\end{array}
\end{aligned}
$$

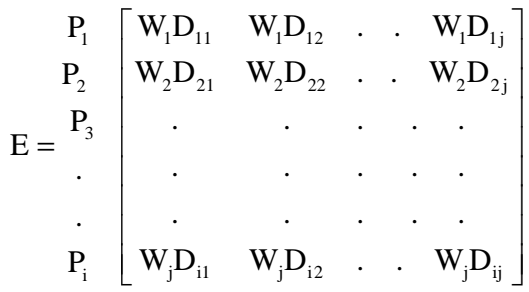

Then, find the following values:

$\mathrm{d}_{\mathrm{j}}=$ Modulus at time interval/kilometer “ $\mathrm{j}$ ”

$\alpha_{\mathrm{j}}=$ Angle between modulus and projection

$\mathrm{T}_{\mathrm{j}}=$ Projection at time interval/kilometer “ $\mathrm{j}$ ”

The relations of these three values are shown in Fig. 1.

By using the following formula:

$$
\operatorname{Cos}(\alpha)=r_{j}=\frac{\sum_{i=1}^{n} W_{i} D_{i j} \times W_{i}}{\sqrt{\sum_{i=1}^{n}\left[W_{i} D_{i j}\right]^{2} \times} \sqrt{\sum_{i=1}^{n}\left[W_{i}\right]^{2}}}
$$

and:

$$
\begin{aligned}
& d_{j}=\sqrt{\left[\sum_{i=1}^{n} W_{i} D_{i j}\right]^{2}} \quad i=1,2, \ldots, n \text { and } j=1,2, \ldots, m \\
& T_{j}=d_{j} \times r_{j}=d_{j} \times \cos (\alpha) \quad j=1,2, \ldots, m
\end{aligned}
$$

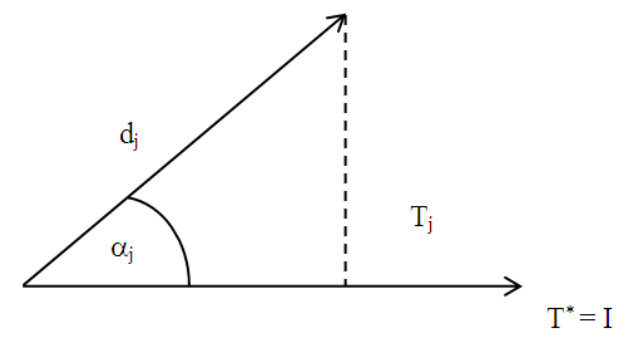

Fig. 1: The relation among $d_{j}, \alpha_{j}$ and $T_{j}$ 
The gained $T_{j}$ value is a Remaining Useful Life (RUL) of the lubricant, which should be converted to $100 \%$ when compared against mileage of cars.

\section{MATERIALS AND METHODS}

The used BP SAE 40 API CD/SF lubricant from 4, 6 and 10-wheel trucks at the mileages of $0,5000,7500$ and $10000 \mathrm{~km}$ was tested for its remaining useful life. After that, the sampling mileage was increased 1000 $\mathrm{km}$ at a time. Four variables which affect useful life of lubricant-Total Base Number (TBN), kinematic viscosity, flash point and amount of Iron-were studied.

\section{RESULTS}

Use of Analytical Hierarchy Process (AHP): The vector projection approach could be used to define an interval change of lubricant when certain variable is deteriorated. Lubricant is best changed when the viscosity is deteriorated in order to preserve the engine. On the contrary, change of lubricant according to value of metals' deterioration does not preserve the engine and can cause engine's damage. Thus, the AHP is used to define a suitable interval change of lubricant in order to achieve maximum efficiency and to preserve the engine.

Step 1: Define weight for each variable.

From the study, variables should be weighted as follow:

$\begin{array}{ll}\text { TBN } & =9 \\ \text { Viscosity } & =8 \\ \text { Flash Point } & =2 \\ \text { Iron } & =1\end{array}$

Step 2: Construct a matrix for paired-comparison against decision-making criteria:

$\mathrm{P}_{12}=1$ from $\mathrm{P}_{1}-\mathrm{P}_{2}=9-8=1$

$P_{21}=1 / P_{12}=1$ is a reversed value

As shown in Table 3.

Step 3: Use the sum value of each position to divide all values in the position: e.g., sum value of the 1 st position:

$$
1+1+1 / 7+1 / 8=2.268
$$

Use this sum value to divide all values in the 1 st position: e.g., $\mathrm{P}_{11}=1 / 2.268=0.441$ and find average value of each row as shown in Table 4 .

Step 4: Find average value of the horizontal sum of each row: e.g., average sum of the 1 st row is:

$$
(0.441+0.433+0.467+0.471) / 4=0.453
$$

Step 5: Multiply value from Step 2 with value from Step 4:

$$
\left[\begin{array}{llll}
0.453 & 0.421 & 0.065 & 0.061
\end{array}\right] \times\left[\begin{array}{cccc}
1 & 1 & 7 & 8 \\
1 & 1 & 6 & 7 \\
1 / 7 & 1 / 6 & 1 & 1 \\
1 / 8 & 1 / 7 & 1 & 1
\end{array}\right]
$$

Results should be as shown in Table 5.

Step 6: Divide value from Step 5 with value from Step 4:

$1.815 / 0.453=4.006,1.690 / 0.421=4.014,0.261 / 0.065$ $=4.015,0.243 / 0.061=3.983$

Then, find Eigen value:

$$
\lambda_{\max }=(4.006+4.014+4.015+3.983) / 4=4.005
$$

Step 7: Find Consistency Index (CI):

$$
\mathrm{CI}=\frac{\lambda_{\max }-\mathrm{n}}{\mathrm{n}-1}=(4.005-4) /(4-1)=0.002
$$

Step 8: Check Consistency Ratio (CR) of variables. $=0.9$ :

Using RI value from Table 3 with a matrix of $4 \times 4$

$$
\mathrm{CR}=\frac{\mathrm{CI}}{\mathrm{RI}}=0.002 / 0.9=0.002
$$

Table 4: Percentage of each attribution and their average (priority vector)

\begin{tabular}{llllll}
\hline Criterion for decision making & $\mathrm{P} 1$ & $\mathrm{P} 2$ & $\mathrm{P} 3$ & $\mathrm{P} 4$ & Mean \\
\hline TBN P1 & 0.441 & 0.433 & 0.467 & 0.471 & 0.453 \\
Kinematic viscosity at $100^{\circ} \mathrm{C}$ P2 & 0.441 & 0.433 & 0.400 & 0.412 & 0.421 \\
Flash point P3 & 0.063 & 0.072 & 0.067 & 0.059 & 0.065 \\
Iron P4 & 0.055 & 0.062 & 0.067 & 0.059 & 0.061 \\
\hline
\end{tabular}

Table 5: The priority vector multiply the reciprocal matrix expression Criterion for decision making

\begin{tabular}{ll}
\hline TBN P1 & 1.815 \\
Kinematic viscosity at $100^{\circ} \mathrm{C}$ P2 & 1.690 \\
Flash point P3 & 0.261 \\
Iron P4 & 0.243 \\
Summation & 4.008 \\
\hline
\end{tabular}


Note if $\mathrm{CR}$ is $<0.1$, variables are given accurate weights.

Step 9: Gain weight of variable used to define interval change of lubricant.

By finding vertical sum value of Step 5:

$$
\begin{gathered}
1.815+1.690+0.261+0.243=4.008 \\
{\left[\begin{array}{c}
\mathrm{W}_{1} \\
\mathrm{~W}_{2} \\
\mathrm{~W}_{3} \\
\mathrm{~W}_{4}
\end{array}\right]=\left[\begin{array}{c}
1.815 / 4.008 \\
1.690 / 4.008 \\
0.261 / 4.008 \\
0.243 / 4.008
\end{array}\right]=\left[\begin{array}{l}
0.453 \\
0.422 \\
0.065 \\
0.061
\end{array}\right]}
\end{gathered}
$$

This gives weights of variables used to define interval change of lubricant, as shown in Table 6.

From Table 6, the lubricant's life of $100 \%$ consists of $\mathrm{TBN}=45.3 \%$, Viscosity $=42.2 \%$, Flash Point $=$ $6.5 \%$ and Iron $=6.1 \%$ according to AHP process.

Lubricant's life gained from AHP process is a single sum of various variables that affect the use of lubricant.

Use of vector projection approach: Some variables that affect condition of lubricant show upward trend to deteriorate beyond acceptable value (e.g., contamination of sand and wear-and-tear of metal) while some variables show downward trend to deteriorate beyond acceptable value (e.g., viscosity, flash point and total base number). Thus, the Vector Projection Approach can make all variables deteriorate in the same trend:

Step 1: Test variables that affect condition of lubricant according to changing mileage as shown in Table 7.

Step 2: Compare the tested value with acceptable value of the lubricant as in Table 8 .

Table 6: Percentage with weighting of each attribution

\begin{tabular}{lll} 
TBN & P1 & 0.453 \\
Viscosity & P2 & 0.422 \\
Flash point & P3 & 0.065 \\
Iron & P4 & 0.061 \\
Summation & & 1.000 \\
\hline
\end{tabular}

Table 7: Values of lubricant attribution of the tested vehicle

\begin{tabular}{lrrrrl}
\hline Criterion for & \multicolumn{2}{l}{ Distance $(\mathrm{km})$} & & & \\
decision making & \multicolumn{1}{c}{$-\mathrm{c}$} & 5.000 & \multicolumn{1}{c}{7.543} & 11.513 & Unit \\
\hline TBN & 7.60 & 5.80 & 5.20 & 4.76 & $\mathrm{mgKOH} \mathrm{g}^{-1}$ \\
Kinematic viscosity & 14.39 & 12.54 & 11.28 & 10.20 & $\mathrm{cSt}^{\circ}$ \\
at $100^{\circ} \mathrm{C}$ & & & & & \\
$\begin{array}{l}\text { Flash point } \\
\text { Iron }\end{array}$ & 240.00 & 228.00 & 223.00 & 221.00 & $\mathrm{C}$ \\
& 0.00 & 16.00 & 21.00 & 33.00 & $\mathrm{ppm}$ \\
\hline
\end{tabular}

Step 3: Compare the tested value with acceptable value using the formula of vector projection approach.

Formula of vector projection approach:

For variables with upward trend: (Silicon and Iron):

$$
\mathrm{D}_{\mathrm{ij}}=\left[\frac{\mathrm{b}_{\mathrm{ij}}-\text { UpperLimit }}{\text { LowerLimit }- \text { UpperLimit }}\right]
$$

For variables with downward trend: (Viscosity, flash point and $T B N)$ :

$$
\mathrm{D}_{\mathrm{ij}}=\left[\frac{\mathrm{b}_{\mathrm{ij}}-\text { LowerLimit }}{\text { UpperLimit }- \text { LowerLimit }}\right]
$$

$b_{i j}$ is value gained from the field test.

Step 4: From Step 3, percentage of variables that affect condition of lubricant could be gained as in Table 9.

Step 5: Find suitable interval change of lubricant with AHP and vector projection approach.

Multiply weight of variables from AHP with results from vector projection approach to gain useful life of lubricant which changes with mileage. After that, use lubricant's life to define suitable interval as shown

\begin{tabular}{|c|c|c|c|c|}
\hline Oil property & Standard & Unit & Limitation & $\begin{array}{l}\text { Standard } \\
\text { of BP SAE } \\
40 \mathrm{CD} / \mathrm{SF}\end{array}$ \\
\hline $\begin{array}{l}\text { Kinematic viscosity } \\
\text { at } 100^{\circ} \mathrm{C}\end{array}$ & ASTM D445 & $\mathrm{cSt}$ & $\pm 25 \%$ & 14.39 \\
\hline Flash point & ASTM D92 & ${ }^{\circ} \mathrm{C}$ & $270-160$ & 240 \\
\hline TBN & ASTM D4739 & $\mathrm{mgKOH} \mathrm{g}^{-1}$ & $-50 \%$ new oil & 7.60 \\
\hline Iron & ASTM D6595 & ppm & $<200$ & 0.00 \\
\hline
\end{tabular}
in Table 10.

Table 8: The acceptable limits and their working range of the lubricant attribution

Table 9: The normalized quantitative value of attribution

\begin{tabular}{llll}
\hline & & & \\
\hline$D_{\mathrm{ij}}$ & & & \\
$-\mathrm{m}$ & & & \\
$0 \mathrm{~km}$ & $5000 \mathrm{~km}$ & $7500 \mathrm{~km}$ & $11513 \mathrm{~km}$ \\
\hline 1 & 0.526 & 0.368 & 0.252 \\
1 & 0.486 & 0.136 & -0.163 \\
0.72 & 0.618 & 0.572 & 0.554 \\
1 & 0.920 & 0.895 & 0.835 \\
\hline
\end{tabular}

Table 10: Conversion of the normalized quantitative value to weight normalized value

\begin{tabular}{llll}
\hline $\mathrm{E}=[\mathrm{D}][\mathrm{W}]$ & & & \\
\hline $0 \mathrm{~km}$ & $5,000 \mathrm{~km}$ & $7,543 \mathrm{~km}$ & $11,513 \mathrm{~km}$ \\
\hline 0.453 & 0.238 & 0.166 & 0.114 \\
0.422 & 0.205 & 0.057 & -0.068 \\
0.046 & 0.040 & 0.034 & 0.036 \\
0.061 & 0.056 & 0.054 & 0.050 \\
\hline
\end{tabular}


Am. J. Engg. \& Applied Sci., 3 (2): 470-475, 2010

Table 11: Calculations of parameters along with the distance

\begin{tabular}{lllll}
\hline Distance $(\mathrm{km})$ & 0 & 5,000 & 7,543 & 11,513 \\
\hline $\mathrm{d}_{\mathrm{j}}$ & 0.624 & 0.321 & 0.186 & 0.146 \\
$\operatorname{Cos}(\alpha)$ & 1.000 & 0.998 & 0.897 & 0.307 \\
$\mathrm{~T}_{\mathrm{j}}$ & 0.624 & 0.320 & 0.167 & 0.045 \\
RUL in percentage & 62.4 & 32.0 & 16.7 & 4.5 \\
Corrected RUL & 100 & 51.28 & 26.76 & 7.2 \\
\hline
\end{tabular}

Step 6: Find the following values:

$\mathrm{d}_{\mathrm{j}}=$ Modulus at time interval/kilometerage

$\alpha_{\mathrm{j}}=$ Angle between modulus and projection

$\mathrm{T}_{\mathrm{j}}=$ Projection at time interval /kilometerage

Lubricant's life by mileage could be gained as shown in Table 11.

\section{DISCUSSION}

The advantage of this method is to show trends in characteristic change of various indicators, thus, remaining useful life can be predicted. Consequently, maintenance is more effective. Results from the study for one logistic company which used to change lubricant every 5,000 km reveal that, when AHP and Projection Approach were used for analysis, the suitable interval change of lubricant was at every $12,000 \mathrm{~km}$. Hence, about $50 \%$ of usable lubricant was wasted. Besides the cost of lubricant, other additional losses, such as opportunities in goods transport which may be more than the cost of lubricant itself, were also wasted.

\section{CONCLUSION}

This research used AHP to find relationship between indicators and used Projection Approach to convert the relationship values of indicators into values of lubricant's characteristics measured by mileage. When these values were compared against acceptable values of the lubricant, remaining useful life of lubricant by mileage could be defined. The remaining useful life of $0 \%$ indicates that the characteristics of lubricant are not sufficient for use. The result from the present study shows that the multi criteria decision making can be used to determine the useful life of the lubricant oil. The method is reasonable rather than the use of any one variable.

\section{REFERENCES}

Al-Harbi, K.M.A.S., 2001. Application of the AHP in project management. Int. J. Project Manage., 19: 19-27. DOI: 10.1016/S0263-7863(99)00038-1

Bevilacqua, M. and M. Braglia, 2000. The analytic hierarchy process applied to maintenance strategy selection. Reliab. Eng. Syst. Safe., 70: 71-83.

Chen, L. and J. Cai, 2003. Using vector projection method to evaluate maintainability of mechanical system in design review. Reliab. Eng. Syst. Safe., 81: 147-154.

Mukherjee, P.S., A.M. Sinha and A. De, 2000. RULL assessment by FTIR- a case study on HEMM in Indian mines. Ind. Lubricat. Tribol., 52: 61-66.

Saaty, T.L., 1994. The Fundamentals of DecisionMaking and Priority Theory with the Analytic Hierarchy Process. RWS Publication, Pittsburg.

Saaty, T.L. and K.P. Kearns, 1991. Analytical Planning: The Organization of System: The Analytical Hierarchy Process Series. RWS Publication, Pittsburg.

Sharma, B.C. and O.P. Gandhi, 2006. RUL assessment of lube oil using AHP and vector projection approach. Ind. Lubricat. Tribol., 58: 187-194.

Shyjith, K., M. Ilangkumaran and S. Kumanan, 2008. Methodology and theory multi-criteria decisionmaking approach to evaluate optimum maintenance strategy in textile industry. J. Qual. Mainten. Eng., 14: 375-386.

Sinha, A.N., P.S. Mukherjee and A. De, 2000. Assessment of useful life of lubricants using artificial neural network. Ind. Lubricat. Tribol., 52: 105-109. 